\title{
Extreme, but not moderate climate scenarios, impart sublethal effects on polyps of the Irukandji jellyfish, Carukia barnesi
}

\author{
Sheldon Rey Boco *, Kylie A. Pitt, Steven D. Melvin \\ Australian Rivers Institute, School of Environment and Science, Griffith University, Southport, Queensland 4215, Australia
}

A R T I C LE INFO

Article history:

Received 3 April 2019

Received in revised form 28 May 2019

Accepted 29 May 2019

Available online xxx

Editor: Daniel Wunderlin

Keywords:

Ocean acidification

Climate change

Interactive effects

Irukandji

Metabolomics

Behavior

\begin{abstract}
A B S T R A C T
Ocean acidification and warming, fueled by excess atmospheric carbon dioxide, can impose stress on marine organisms. Most studies testing the effects of climate change on marine organisms, however, use extreme climate projection scenarios, despite moderate projections scenarios being most likely to occur. Here, we examined the interactive effects of warming and acidification on reproduction, respiration, mobility and metabolic composition of polyps of the Irukandji jellyfish, Carukia barnesi, to determine the responses of a cubozoan jellyfish to moderate and extreme climate scenarios in Queensland, Australia. The experiment consisted two orthogonal factors: temperature (current $25^{\circ} \mathrm{C}$ and future $28^{\circ} \mathrm{C}$ ) and $\mathrm{pH}$ (current (8.0) moderate (7.9) and extreme (7.7)). All polyps survived in the experiment but fewer polyps were produced in the $\mathrm{pH} 7.7$ treatment compared to $\mathrm{pH} 7.9$ and $\mathrm{pH} 8.0$. Respiration rates were elevated in the lowest $\mathrm{pH}$ treatment throughout most of the experiment and polyps were approximately half as mobile in this treatment compared to $\mathrm{pH} 7.9$ and $\mathrm{pH} 8.0$, regardless of temperature. We identified metabolites occurring at significantly lower relative abundance in the lowest pH (i.e. glutamate, acetate, betaine, methylguanidine, lysine, sarcosine, glycine) and elevated temperature (i.e. proline, trigonelline, creatinine, mannose, acetate, betaine, methylguanidine, lysine, sarcosine) treatments. Glycine was the only metabolite exhibiting an interactive effect between $\mathrm{pH}$ and temperature. Our results suggest that $C$. barnesi polyps are unaffected by the most optimistic climate scenario and may tolerate even extreme climate conditions to some extent.
\end{abstract}

\section{Introduction}

Excess atmospheric $\mathrm{CO}_{2}$ lowers $\mathrm{pH}$ and raises the temperature of the oceans (Doney, 2010). Ocean acidification and warming are expected to intensify based on recent climate change projections (i.e. Representative Concentration Pathways) (Hartmann et al., 2013; Camp et al., 2018) and can stress marine fauna (Pörtner et al., 2005; Pandolfi et al., 2011; Doney et al., 2012). Many experiments that aim to test the responses of coastal biota to ocean acidification, however, use experimental conditions that do not reflect conditions biota experience in the field (Wahl et al., 2016; Jarrold et al., 2017). For example, experiments usually expose biota to constant levels of partial pressure of $\mathrm{CO}_{2}\left(p \mathrm{CO}_{2}\right)$ predicted for oceanic environments (Wahl et al., 2016). Coastal waters, however, usually experience large diel fluctuations of $p \mathrm{CO}_{2}$ because photosynthesis, and uptake of $\mathrm{CO}_{2}$, ceases at night (Waldbusser and Salisbury, 2014; Wahl et al., 2016). Indeed, nocturnal levels of $p \mathrm{CO}_{2}$ can exceed the most dire climate change projections (Duarte et al., 2013; Hughes et al., 2017; Jarrold et al., 2017). Moreover, experiments usually test the most extreme climate change projections (e.g. Representative Concentration Pathway (RCP) 8.5) when in fact moderate projections (e.g. RCP 2.6) are accepted as being more likely to occur (Hughes et al., 2017). Hence,

\footnotetext{
* Corresponding author at: Australian Rivers Institute, Griffith University, Building
} G24, Southport QLD 4215, Australia.

Email address: sheldonrey.boco@griffithuni.edu.au (S.R. Boco) to ensure their environmental relevance, experiments testing the effects of ocean acidification on coastal biota should mimic the diel fluctuations in $p \mathrm{CO}_{2}$ that biota experience in the field and test a range of possible climate change scenarios, from moderate to extreme.

Climate stressors can induce a range of sublethal responses that manifest in morphology, physiology, behavior and other endpoints (Rand, 1995). Such sublethal effects can impair fundamental higher-level processes, such as reproduction, feeding, and predator avoidance, all of which can ultimately lead to death (Rand, 1995; Walker, 2008). Interactions between stressors must also be considered, since combined stressors may elicit different responses than individual stressors (Riebesell and Gattuso, 2015). For example, warming and low $\mathrm{pH}$ as isolated stressors had no effect on growth of polyps of the coral Porites panamensis, but growth was significantly reduced when polyps were exposed to both stressors simultaneously (Anlauf et al., 2011). Whether stressors occur individually or combined, molecular and cellular initiating events represent the physiological basis for many higher-level effects related to their occurrence (Kültz, 2005). New analytical techniques such as untargeted metabolomics have led to major breakthroughs in our ability to broadly explore the mechanistic basis of how stressors influence molecular and cellular processes (Viant, 2007; Bundy et al., 2009). Similarly, recent technological advances in image recognition have facilitated the study of higher-level behavioral responses in aquatic species, including those caused by a range of environmental stressors (Melvin and Wilson, 2013). Despite considerable advances in metabolomics and be- 
havioral analysis techniques, few studies have combined these tools to better understand how climatic stressors might influence aquatic species.

Climate change stressors influence a variety of physiological and behavioral responses of marine fauna (Nagelkerken and Munday, 2016). For example, the Caribbean coral Acropora cervicornis increased feeding, increased lipid content and expanded the polyp body and tentacles under elevated $p \mathrm{CO}_{2}(800 \mathrm{ppm})$ to mitigate hypercapnia stress (Towle et al., 2015). The behavior of some species is also negatively affected by exposure to elevated $p \mathrm{CO}_{2}$. For example, larval fish altered swimming patterns and reduced velocity and swimming duration (Rossi et al., 2015; Nagelkerken and Munday, 2016) and the scleractinian coral Stylophora pistillata reduced feeding rate (Houlbrèque et al., 2015) when exposed to elevated $p \mathrm{CO}_{2}$. Furthermore, climate stressors may act synergistically to debilitate marine invertebrates including mollusks, echinoderms and cnidarians (Byrne et al., 2017). A meta-analysis of the interactions of warming and acidification on the early life stages of marine invertebrates revealed that synergistic interactions are common ( $76 \%$ of the studies examined) since low $\mathrm{pH}$ can induce sublethal effects such as reduced growth and impaired metabolism, which may be exacerbated if thermal thresholds are exceeded (Przeslawski et al., 2015; Byrne et al., 2017). Climatic stressors such as increased temperature and low $\mathrm{pH}$ may induce metabolic depression since maintaining acid-base equilibria under such conditions is physiologically costly (Portner, 2008). Unless adaptations are present, this metabolic depression may lead to negative physiological performance or death. This concept however, requires testing the physiological and metabolomic responses of biota under different levels of a stressor, e.g. low or high $p \mathrm{CO}_{2}$ (Kroeker et al., 2013; Sogin et al., 2016).

Jellyfish are a conspicuous component of coastal marine ecosystems and are renowned for causing spectacular and, sometimes problematic, blooms. Jellyfish exhibit varied physiological and behavioral responses to ocean acidification (Klein et al., 2014; Algueró-Muñiz et al., 2016; Tills et al., 2016). Large differences in responses have even been detected within species. For example, some studies have shown that the physiology and behavior of ephyrae (juvenile medusae) of the common Moon jellyfish, Aurelia aurita, are unaffected by extreme $p \mathrm{CO}_{2}$ (up to 4000-5000 $\mu \mathrm{atm}$ ) (Kikkawa et al., 2010; Algueró-Muñiz et al., 2016), whereas Tills et al. (2016) observed reduced pulsation and swimming of $A$. aurita ephyrae at much lower (but still elevated) $p \mathrm{CO}_{2}$ levels $(\sim 1000 \mu \mathrm{atm})$. These studies indicate that physiology and behavior are sensitive endpoints in organisms exposed to ocean acidification and warming, but the discrepancies in the literature highlight a need for more research on the topic, with rigorous control of experimental conditions.

Some studies suggest that jellyfish are robust to climate change stressors (see Klein et al., 2014; Algueró-Muñiz et al., 2016; Klein et al., 2017) however, relatively few species have been tested and the responses of those species may not reflect the majority of jellyfish species (Pitt et al., 2018). Carukia barnesi is arguably the most economically and medically important cubozoan jellyfish species found in northern Queensland, Australia (Courtney et al., 2016a). C. barnesi is carybdeid cubozoan with translucent bell covered with prominent mamillations (or warts) (Southcott, 1967; Underwood and Seymour, 2007). Like all cubozoans, $C$. barnesi has a metagenic life cycle that consists of pelagic medusa and benthic polyp stages. The medusae occur seasonally along north-eastern Australia typically from November to May (Courtney et al., 2016a) but the polyps have never been located in the field. The polyps can reproduce asexually through the production of swimming polyps that develop as lateral buds that break free from the parent polyp and swim away (Courtney et al., 2016a). After several days, swimming polyps will settle on favorable substrate and develop back into mature polyps. C. barnesi medusae can invoke Irukandji syndrome, a suite of debilitating symptoms that are occasionally fatal and may require treatment in hospital (Pereira et al., 2010; Courtney et al., 2016a). C. barnesi is considered responsible for most of the Irukandji envenomations in northern Queensland (Gershwin et al., 2013) and the estimated annual cost of treating Irukandji stings in northern Australia alone is AUD 1-3 million (Fenner, 1999; Carrette et al., 2012). Responses of only one other species of cubozoan jellyfish (polyps of Alatina alata) to ocean acidification and temperature scenarios have been studied (Klein et al., 2014, 2017). They found that $A$. alata polyps generally survived extreme ocean acidification and temperature scenarios but that their fitness (in terms of rates of asexual reproduction, feeding and respiration) was impaired. Given the medical and economic importance of Irukandji species, it is imperative that we study the responses of a range of Irukandji species, and focus particular attention on sub-lethal responses.

We examined individual and combined effects of ocean warming and acidification on behavior, survival, asexual reproduction, respiration, and metabolic composition of polyps of Carukia barnesi. We hypothesised that polyps exposed to high $p \mathrm{CO}_{2}$ and elevated temperature in combination would be less mobile, have lower rates of asexual reproduction and higher rates of respiration. We also hypothesised that metabolite composition of polyps in high $p \mathrm{CO}_{2}$ and elevated temperature in combination would vary from those of the other treatments.

\section{Materials and methods}

\subsection{Experimental design}

The experiment consisted of two orthogonal factors: temperature [two levels: current $\left(25^{\circ} \mathrm{C}\right)$ and future $\left.\left(28^{\circ} \mathrm{C}\right)\right]$ and $\mathrm{pH}$ [three levels: current (8.0) moderate (7.9) and extreme (7.7)]. The experiment was conducted in a controlled temperature (CT) laboratory maintained at $22^{\circ} \mathrm{C}$, with aquaria placed in individual water baths that were heated with submersible heaters to achieve the desired temperatures. The ambient temperature $\left(25^{\circ} \mathrm{C}\right)$ was based on present-day temperatures of the most likely habitat of $C$. barnesi polyps in Northern Queensland (Courtney et al., 2016b). The high temperature treatment was based on the A1F1 scenario for the sea surface temperature increase of Australia (except for southern waters of Australia) (Reisinger et al., 2014). The $\mathrm{pH}$ treatments were based on target atmospheric $\mathrm{CO}_{2}$ concentrations (in ppm) including 400 (for current pH), 500 (the highest concentration of optimistic greenhouse gas emission for at least the next century (IPCC, 2014; Hughes et al., 2017)) and 1000 (the most extreme (RCP 8.5) scenario (IPCC, 2014).

\subsection{Experimental animals}

Polyp cultures used in the experiment originated from planula larvae that were collected from adult $C$. barnesi medusae sampled near Double Island, North Queensland, Australia $\left(16^{\circ} 43.50 \mathrm{~S}, 145^{\circ} 41.00 \mathrm{E}\right)$ during January and December 2014 and April 2015 (Courtney et al., 2016a). Swimming polyps (i.e. mobile buds that detach from polyps) (Courtney et al., 2016a) from laboratory cultures maintained at $\sim 25^{\circ} \mathrm{C}$ and salinity $\sim 35$ PSU were transferred to $25 \mathrm{~mL}$ plastic petri dishes, where they metamorphosed into attached polyps. Two polyps were also settled on abraded plastic plates $(6 \mathrm{~mm}$ width, $23 \mathrm{~mm}$ length) and one plate was placed within an uncapped $4 \mathrm{~mL}$ respiration vial to use for respiration measurements. One polyp dish with 15 at- 
tached polyps and two respiration vials (one that contained a plate with polyps and one with a plate lacking polyps) were immersed within $1 \mathrm{~L}$ beakers and eight replicate beakers were randomly assigned to each treatment. Prior to the experiment, polyps were gradually transitioned into their experimental conditions. Polyps were transitioned into the warmer treatments at a rate of $1^{\circ} \mathrm{Cd}^{-1}$ and into their lower $\mathrm{pH}$ treatments at a rate of 0.1 and $0.15 \mathrm{pH}$ per day respectively for the moderate and extreme $\mathrm{pH}$ treatments. Every third day polyps were transferred to separate aquaria and fed newly hatched Artemia sp. nauplii that had been hatched from cysts in the laboratory. Each replicate polyp dish was allocated $\sim 50$ nauplii. Polyps were observed using a dissecting microscope, and the number of polyps and their developmental stage (i.e. parent polyp, budding or partial fission, swimming polyp, medusa) were recorded. During feeding, polyps were maintained at the appropriate temperature and $\mathrm{pH}$ treatments using water from their respective aquaria and water baths.

\subsection{Manipulation and analysis of seawater chemistry}

To achieve the desired water chemistry of each treatment, a series of gas proportioners were used to deliver $\mathrm{CO}_{2}, \mathrm{~N}_{2}$, and $\mathrm{O}_{2}$ gas to seawater. The desired gas compositions were mixed from individual gas cylinders using 12 Omega mass flow controllers (FMA-5400 s, 0-20 mL min ${ }^{-1}\left(\mathrm{CO}_{2}\right), 0-5 \mathrm{~L} \mathrm{~min}^{-1}\left(\mathrm{~N}_{2}\right), 0-2 \mathrm{~L} \mathrm{~min}^{-1}\left(\mathrm{O}_{2}\right)$ (Bockmon et al., 2013). Ambient DO and $\mathrm{pH}$ values and the magnitude of daily cycles were based on empirical measurements of diel variability at Moreton Bay, Queensland $\left(27.13^{\circ} \mathrm{S}, 153.07^{\circ} \mathrm{E}\right)$ in November 2014, and observations in a lagoon at Heron Island in the southern Great Barrier Reef (Georgiou et al., 2015). Salinity, temperature, dissolved oxygen (DO), and $\mathrm{pH}$ were measured in all experimental aquaria at 12:00 and 19:00 every third day. Salinity and temperature were measured using a conductivity-salinity meter (TPS salinity-conductivity meter, MC-84) and thermometer, respectively. DO concentrations were recorded using an optic DO sensor (OptiOx, Mettler Toledo Ltd) and $\mathrm{pH}$ was measured using a Five Go $\mathrm{pH}$ meter (Mettler Toledo Ltd) equipped with an Inlab Expert Pro Electrode (Mettler Toledo Ltd). Every $2-3 \mathrm{~d}$, pH electrodes were calibrated using TRIS/HCl buffers in synthetic seawater to ensure accurate measurements of $\mathrm{pH}$ in the seawater carbonate system (Dickson et al., 2007). To accurately measure diel patterns of $\mathrm{pH}$ during the experiment, $\mathrm{pH}$ measurements were taken hourly (between 0600 and 1800 h) from one randomly selected replicate from each of the treatments once per week (Supplementary Fig. 1). Every third day, a $100-\mathrm{mL}$ water sample was collected for total alkalinity (TA) analysis from one randomly selected replicate from each of the treatments (Supplementary Table 1). Samples of seawater were collected in clean amber glass bottles using a drawing tube and overfilled for $10 \mathrm{~s}$ to minimise gas exchange between the sample water and the atmosphere. Samples were filtered through $0.22-\mu \mathrm{m}$ filters, sealed tightly, and immediately analysed. Samples for TA $(80 \mathrm{~mL})$ were analysed using a Mettler Toledo titrator, which was calibrated using TRIS/HCl buffers in synthetic seawater and verified with certified TA reference material (provided by A. G. Dickson, batch\#162).

\subsection{Respiration measurements}

Respiration rates of the two polyps attached to the respiration plates were measured on day 0 and every 1-3 days thereafter. Oxygen consumption was also measured in control vials (i.e. without polyps) to account for the respiration of bacterial communities and other microorganisms that may have formed during the experiment. Prior to measurements, vials were removed from their aquaria and inspected.
Any newly produced polyps were removed so that only the original two parent polyps remained. The water within each vial was filled to overflowing with $0.22 \mu \mathrm{m}$ filtered seawater of the appropriate treatment and then sealed. Oxygen concentrations were measured using a FireSting $\mathrm{O}_{2}$ optode (Pyroscience, Germany) at the beginning and end of a three-hour dark incubation. Oxygen consumption rates were measured per polyp (unit: g $_{2}$ polyp $^{-1} \mathrm{~h}^{-1}$ ).

\subsection{Video recording and analysis of polyp movements}

Movements of one polyp per replicate were quantified at the beginning and end of the experiment. Polyps were recorded using the S-eye software installed in a CellPad tablet attached to a dissecting microscope (Prism Optical). A special recording chamber was constructed, consisting of a piece of black cardboard fixed to the bottom of the polyp dish with the dish placed on the illuminated microscope stage (Supplementary Fig. 2). This set-up enabled light to surround the edge of the dish but not penetrate directly through the dish, thereby increasing contrast. A white paper cone was placed on top of the dish to disperse light to the polyps (Supplementary Fig. 2). The videos were analysed using the software Ethovision XT 9.0 (Nodulus Information Technology, Netherlands). The mobility of polyps (\%) was calculated as:

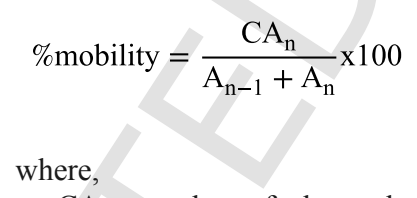

$\mathrm{CA}_{\mathrm{n}}=$ number of changed pixels between previous and current samples.

$\mathrm{A}_{\mathrm{n}-1}=$ number of pixels in previous sample.

$\mathrm{A}_{\mathrm{n}}=$ number of pixels in current sample.

Extract from newly hatched Artemia nauplii was administered to the polyp dish to stimulate feeding behavior and movement of polyps. The extract was prepared from a solution of 50 Artemia per $\mathrm{ml}$ of filtered seawater that was homogenised using a mortar and pestle (crushed by 30 rotations of pestle) and passed through a $0.20 \mu \mathrm{m}$ filter. The method was adapted from a method used to stimulate feeding in Hydra vulgaris (Pierobon et al., 2004) and tested in a pilot study, which showed polyps were $67 \%$ more mobile (ANOVA $F=26.236$, $p<0.001)$ in the presence of Artemia sp. crude extract. The polyps were acclimated for at least $2 \mathrm{~min}$ after the Artemia extract was added and then filmed for $15 \mathrm{~min}$.

\subsection{Metabolomics}

Twelve polyps from each replicate were harvested at the end of the experiment and pooled for analysis of polar metabolites via Nuclear Magnetic Resonance (NMR) spectroscopy. The polyps were quickly transferred to $2.0 \mathrm{~mL}$ micro-centrifuge tubes, blotted with a Kimwipe, weighed (mg) and $400 \mu \mathrm{l}$ of cold methanol was added and samples stored overnight at $-20^{\circ} \mathrm{C}$. The next day samples were sonicated to enhance metabolite extraction and centrifuged $(10 \mathrm{~min}, 15,000 \mathrm{rpm}$ at $4{ }^{\circ} \mathrm{C}$ ). After centrifugation, the supernatant was transferred to glass amber vials and dried in a centrifugal evaporator (GeneVac). Dried samples were reconstituted with deuterium oxide $\left(\mathrm{D}_{2} \mathrm{O}\right)$ containing 0.05\% sodium-3-(tri-methylsilyl)-2,2,3,3-tetradeuteriopropionate (TSP) as an internal standard. Samples were vortexed and supernatants were transferred to $3 \mathrm{~mm}$ Nuclear Magnetic Resonance (NMR) tubes using glass pipettes. A blank containing $100 \mathrm{~mL}$ Milli-Q water was put through the full extraction and analytical 
workflow to ensure no contamination resulting from sample processing or NMR spectroscopy.

NMR spectra were acquired with an $800 \mathrm{MHz}$ Bruker® Avance III HDX spectrometer. The system was equipped with a Triple (TCI) Resonance $5 \mathrm{~mm}$ Cryoprobe with Z-gradient and automatic tuning and matching, and a SampleJet automatic sample changer controlled via the software IconNMR ${ }^{\mathrm{TM}}$ (Bruker Pty Ltd., Victoria, Australia). Spectra were acquired at $298 \mathrm{~K}$, using $\mathrm{D}_{2} \mathrm{O}$ for field locking and TSP $\left({ }^{1} \mathrm{H} \delta 0.00\right)$ as an internal reference. ${ }^{1} \mathrm{H}$ spectra were acquired using the $\mathrm{zg} 30$ pulse program with 256 scans, $0.8 \mathrm{~s}$ relaxation delay, $7.75 \mu \mathrm{s}$ pulse width and $16 \mathrm{kHz}$ spectral width $\left({ }^{1} \mathrm{H} \delta-3.75-16.28\right)$. Edited ${ }^{1} \mathrm{H}-{ }^{13} \mathrm{C}$ HSQC spectra were acquired for a pooled sample using the pulse sequence hsqcedetgpsisp2.2 with 160 scans, $1.5 \mathrm{~s}$ relaxation delay, $7.83 \mu$ s pulse width and spectral widths of $12.8 \mathrm{kHz}\left({ }^{1} \mathrm{H} \delta\right.$ $-3.23-12.79)$ and $33.1 \mathrm{kHz}\left({ }^{13} \mathrm{C} \delta-9.40-155.2\right)$.

MestReNova v8.1.4 (Mestrelab Research S.L., Spain) was used for post processing of NMR spectra. ${ }^{1} \mathrm{H}$ NMR free induction decay (FID) data were Fourier transformed with line broadening of $0.3 \mathrm{~Hz}$ and HSQC spectra were processed with default Bruker post-processing parameters. All spectra were manually phase corrected, automatically baseline adjusted (ablative), and referenced and normalised to TSP $\left({ }^{1} \mathrm{H} \delta 0.00,{ }^{13} \mathrm{C} \delta 0.0\right)$. Once processed, individual features (resonances) were manually integrated and normalised to the mass of polyps used for extractions to provide a comparative measure of the relative abundance of metabolites.

\subsection{Statistical analyses}

Differences in the number of swimming polyps (as an indicator of asexual reproduction), respiration rates $\left(n \mathrm{O}_{2}\right.$ polyp $\left.{ }^{-1} \mathrm{~h}^{-1}\right)$ and percent (\%) mobility of polyps were analysed using repeated measures linear mixed models (LMMs) in SPSS. The fixed factors were $\mathrm{pH}$, temperature, and day (1-13) as repeated measure. Goodness-of-fit statistics (e.g. -2 restricted log likelihood, Akaike's Information Criterion and Bayesian information criterion) were used to determine the model of best fit. Normality and homoscedasticity of data were checked using standardised residual and Q-Q plots and data were either $\ln$ or $\ln$ $(\mathrm{x}+1)$ transformed. Estimated marginal means (post hoc comparisons of least-squares means) were used to determine which means differed.

Metabolomics data were analysed for visual separation of treatment groups using MetaboAnalyst 4.0 (Xia and Wishart, 2016). After log normalisation and auto-scaling of the data, Permutational Multivariate Analysis of Variance (PerMANOVA) in Primer 7, Principal Component Analysis (PCA) and supervised Partial Least Squares Discriminant Analysis (PLS-DA) were performed to identify overall differences in the metabolite profiles of polyps from the different treatment groups. Individual metabolites were further analysed using two-way ANOVAs in SPSS and Tukey's HSD post-hoc test was used to identify the treatments that differed.

\section{Results}

\subsection{Survival and asexual reproduction}

All polyps of $C$. barnesi survived the experiment and swimming polyps were produced in all treatments. Temperature and $\mathrm{pH}$ both influenced the number of polyps produced over time, but there was no interaction between them (Table 1). At the end of the experiment, approximately twice as many polyps were being produced at $25^{\circ} \mathrm{C}$ than at $28^{\circ} \mathrm{C}$ (Fig. 1a) and the $\mathrm{pH} 7.7$ treatment produced fewer polyps than the $\mathrm{pH} 7.9$ and $\mathrm{pH} 8.0$ treatments (Fig. 1b).
Table 1

Summary of results of a linear mixed-models analysis of the number of swimming polyps $(\mathrm{n}=48)$ produced in each day (days 2, 5, 8 and 11) between treatments in the experiment.

\begin{tabular}{lllll}
\hline Source & $\begin{array}{l}\text { Numerator } \\
\text { df }\end{array}$ & Denominator & & \\
& df & $F$ & $p$ \\
\hline pH & 2 & 35.58 & 15.61 & 0.182 \\
Temperature & 1 & 71.73 & 16.41 & 0.104 \\
Day & 1 & 98.22 & 1.40 & 0.169 \\
pH $\times$ temperature & 2 & 35.58 & 0.697 & 0.980 \\
pH $\times$ day & 2 & 32.56 & 3.60 & $<\mathbf{0 . 0 0 1}$ \\
Temperature $\times$ day & 1 & 98.22 & 17.36 & $<\mathbf{0 . 0 0 1}$ \\
pH $\times$ temperature $\times$ day & 2 & 32.56 & 0.109 & 0.897 \\
\hline
\end{tabular}

The model of best fit is AR (1) Heterogeneous: -2 Restricted Log Likelihood=61.636, Akaike's Information Criterion (AIC) $=117.636$

$d f=$ degrees of freedom.

$p$ values in bold are statistically significant $(p<0.05)$. Data were $\ln (\mathrm{x}+1)$ transformed.
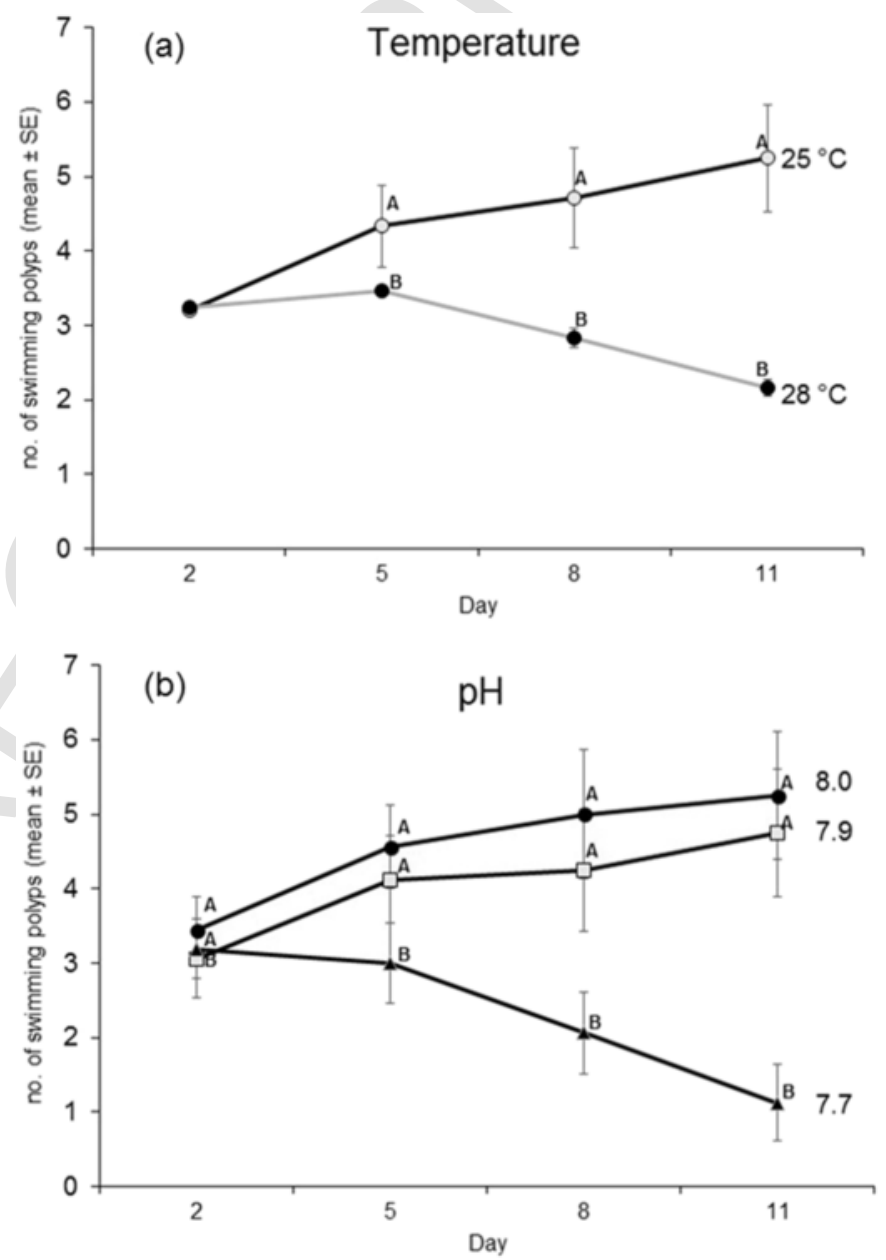

Fig. 1. Number of swimming polyps (mean $\pm \mathrm{SE}$ ) recorded per day in the experiment. Letters above data points indicate similarities (e.g. AA) and differences (e.g. AB) between temperature (a) and $\mathrm{pH}$ (b) treatments within each day based on estimated marginal means.

\subsection{Respiration rates}

Respiration rates were slightly elevated in the high temperature treatment on days 1, 4 and 8 but were otherwise similar throughout the experiment (Table 2: Fig. 2a). Respiration rates were elevated in 
Table 2

Summary of results of a linear mixed-models analysis of the respiration rates of polyps in each day (days $0,1,4,7,8,10$ and 13) between treatments in the experiment.

\begin{tabular}{lllll}
\hline Source & $\begin{array}{l}\text { Numerator } \\
\text { df }\end{array}$ & $\begin{array}{l}\text { Denominator } \\
\text { df }\end{array}$ & $F$ & $p$ \\
\hline pH & 2 & 64.964 & 73.383 & $<\mathbf{0 . 0 0 1}$ \\
Temperature & 1 & 64.964 & 13.052 & $<\mathbf{0 . 0 0 1}$ \\
Day & 6 & 26.304 & 34.861 & $\mathbf{0 . 0 0 1}$ \\
$\mathrm{pH} \times$ temperature & 2 & 64.964 & 4.958 & $<\mathbf{0 . 0 0 1}$ \\
$\mathrm{pH} \times$ day & 12 & 26.304 & 28.115 & $<\mathbf{0 . 0 0 1}$ \\
Temperature $\times$ day & 6 & 26.304 & 5.980 & $<\mathbf{0 . 0 0 1}$ \\
$\mathrm{pH} \times$ temperature $\times$ day & 12 & 26.304 & 1.738 & 0.115 \\
\hline
\end{tabular}

The model of best fit is Diagonal: 2 Restricted Log Likelihood $=-241.319$, Akaike's Information Criterion (AIC) $=-227.319$.

$d f=$ degrees of freedom.

$p$ values in bold are statistically significant $(p<0.05)$. Data were $\ln$ transformed.
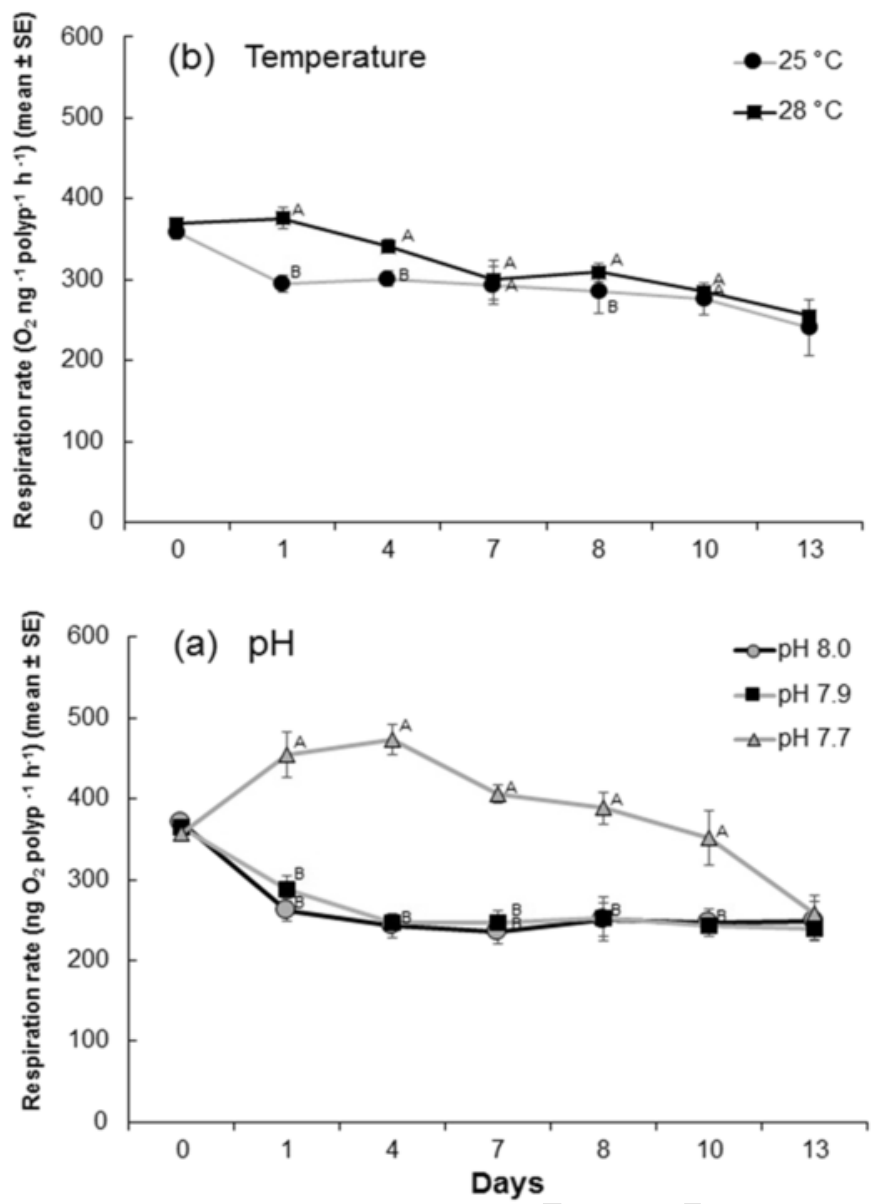

Fig. 2. Respiration rates of polyps (mean \pm SE) in the temperature $\left(25^{\circ} \mathrm{C}, 28^{\circ} \mathrm{C}\right)$ (a) and $\mathrm{pH}(8.0,7.9,7.7)(\mathrm{b})$ treatments throughout the experiment. Letters above data points indicate similarities (e.g. AA) and differences (e.g. AB) between temperature and $\mathrm{pH}$ treatments within each day based on estimated marginal means.

the lowest $\mathrm{pH}$ treatment throughout most of the experiment, but declined and converged towards those in the medium and high $\mathrm{pH}$ treatments by the end of the experiment (Table 2; Fig. 2b). There was no significant interaction between $\mathrm{pH}$, temperature and time in the full-factorial model (Table 2).

\subsection{Mobility}

Polyps were approximately half as mobile in the lowest $\mathrm{pH}$ treatment, regardless of temperature, compared to those at $\mathrm{pH} 7.9$ and $\mathrm{pH} 8.0$. At $25^{\circ} \mathrm{C}$ polyps in the $\mathrm{pH} 8.0$ treatment were slightly less mobile than those in the $\mathrm{pH} 7.9$ treatment (Table 3: Fig. 3). At $28^{\circ} \mathrm{C}$, polyps were less than half as mobile as those at $\mathrm{pH} 7.9$ and $\mathrm{pH} 8.0$ (Table 3: Fig. 3).

Table 3

Summary of results of a linear mixed-models analysis of the mobility of polyps before and after exposure to $\mathrm{pH}$ and temperature treatments in the experiment.

\begin{tabular}{lllll}
\hline Source & $\begin{array}{l}\text { Numerator } \\
\mathrm{df}\end{array}$ & $\begin{array}{l}\text { Denominator } \\
\mathrm{df}\end{array}$ & $F$ & $p$ \\
\hline $\mathrm{pH}$ & 2 & 40.571 & 38.88 & $<\mathbf{0 . 0 0 1}$ \\
Temperature & 1 & 40.571 & 0.036 & 0.851 \\
Before v. after & 1 & 40.571 & 18.61 & $<\mathbf{0 . 0 0 1}$ \\
$\mathrm{pH} \times$ temperature & 2 & 40.571 & 4.79 & $\mathbf{0 . 0 1 4}$ \\
$\mathrm{pH} \times$ before v. after & 2 & 40.571 & 27.72 & $<\mathbf{0 . 0 0 1}$ \\
$\begin{array}{l}\text { Temperature } \times \text { before v. } \\
\quad \text { after }\end{array}$ & 1 & 40.571 & 2.67 & 0.110 \\
pH $\times$ temperature $\times$ before v. & 2 & & & \\
$\quad$ after & & 40.571 & 2.26 & 0.117 \\
\hline
\end{tabular}

The model of best fit is Diagonal: -2 Restricted Log Likelihood=-36.638, Akaike's Information Criterion (AIC) $=-32.638$.

$d f=$ degrees of freedom.

$p$ values in bold are statistically significant $(p<0.05)$. Data were $\ln$ transformed.

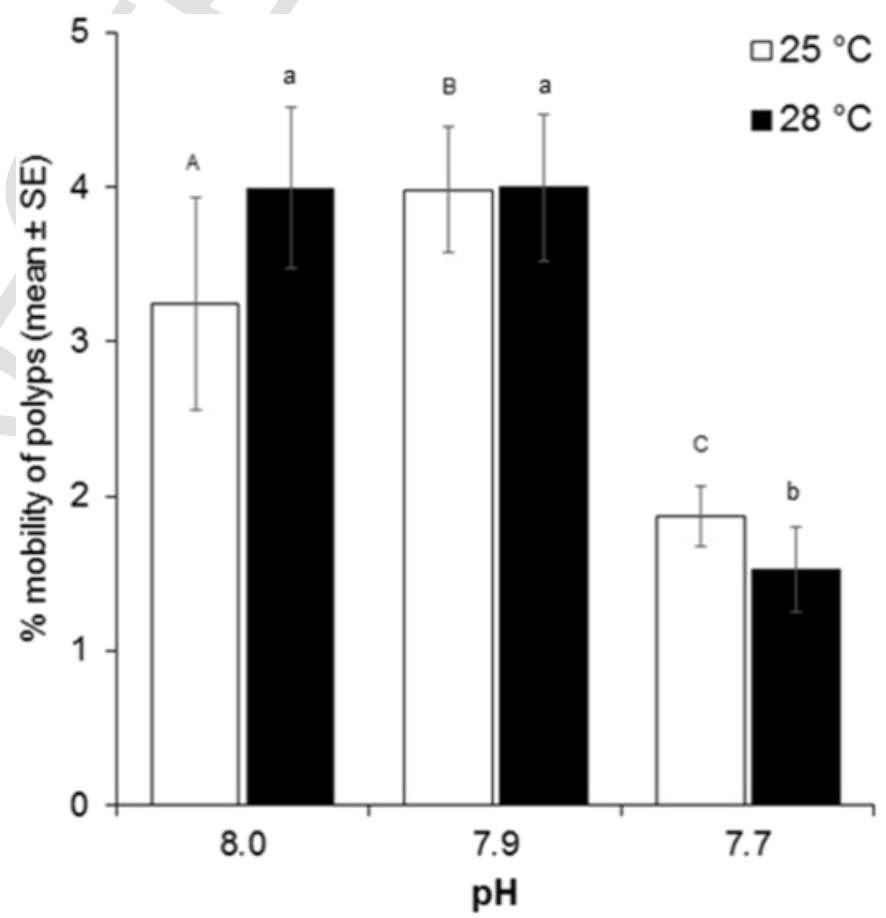

Fig. 3. Percent (\%) mobility of polyps (mean $\pm \mathrm{SE}$ ) in different levels of $\mathrm{pH}$ in ambient $\left(25^{\circ} \mathrm{C}\right)$ (blank bars) and elevated $\left(28^{\circ} \mathrm{C}\right)$ (black bars) temperature scenarios. Averages were calculated from $\%$ mobility before and after exposure to experimental treatments. Letters above error bars indicate similarities (e.g. AA) and differences (e.g. AB) between $\mathrm{pH}$ treatments in each temperature condition based on estimated marginal means. $\mathrm{ABC}$ indicate similarities or differences between the $25^{\circ}$ treatment and 'abc' for the $28^{\circ}$ treatment. 


\subsection{Metabolomics}

Acetate, arabinose, betaine, caproic acid, creatine, homarine, isoleucine, glutamate, glutamine, glycine, lysine, malonic acid, mannose, methylguanidine, proline, sarcosine, taurine, trigonelline, tyrosine and valine were identified in the polyps. While the PerMANOVA was not significant at $\alpha=0.05$, there was a strong trend in the data $(p=0.07)$ (Table 4), and visualisation using PCA and sPLS-DA suggested some differences in metabolite profiles between treatments (Supplementary Fig. 3). As such, we determined that it was appropriate to proceed with statistical analysis of individual metabolites. The ANOVAs of individual metabolites revealed that twelve metabolites varied among treatments (Supplementary Table 2). Acetate, betaine, glycine, methylguanidine, lysine, and sarcosine were relatively less abundant in the $\mathrm{pH} 7.7$ treatment compared to ambient $\mathrm{pH}(\mathrm{pH} 8.0$, Fig. 4). Proline, trigonelline, creatinine, mannose, acetate, betaine, methylguanidine, lysine, and sarcosine also occurred in lower relative abundance in the $28^{\circ} \mathrm{C}$ treatment compared to the ambient temperature $\left(25^{\circ} \mathrm{C}\right)$ treatment (Fig. 5). Glycine was the only metabolite that exhibited significant interactive effects of $\mathrm{pH}$ and temperature treatments. Glycine in the $\mathrm{pH}$ treatments at $28^{\circ} \mathrm{C}$ was significantly less abundant than those of $\mathrm{pH} 8.0$ at $25^{\circ} \mathrm{C}$ (Fig. 6).

Table 4

PerMANOVA model of metabolites of Carukia barnesi polyps exposed to $\mathrm{pH}$ and temperature treatments.

\begin{tabular}{llllll}
\hline Source & Sum of & $\begin{array}{l}\text { Mean } \\
\text { squares }\end{array}$ & square & F & $p$ \\
\hline $\mathrm{pH}$ & 2 & 265.3 & 132.65 & 2.0778 & 0.079 \\
Temperature & 1 & 167.11 & 167.11 & 2.6176 & 0.076 \\
$\mathrm{pH} \times$ temperature & 2 & 128.24 & 64.12 & 1.0044 & 0.36 \\
Residual & 41 & 2617.4 & 63.84 & & \\
Total & 46 & 3174 & & & \\
\hline
\end{tabular}

$d f$ degrees of freedom.

$p$ values in bold are statistically significant $(p<0.05)$.

Based on 10,000 permutations and Bray-Curtis distance.

\section{Discussion}

We found that polyps of Carukia barnesi can survive and reproduce under even the most extreme climate scenario predictions (lowest $\mathrm{pH}$ and elevated temperature), yet we detected several sublethal responses that might influence their overall fitness. Sublethal effects included reduced asexual reproduction, increased respiration rates, reduced mobility and suppression of individual metabolites in extreme conditions. For the most part, effects occurred in response to the stressors individually (i.e., $\mathrm{pH}$ or temperature), thus failing to support our hypotheses that sublethal responses would manifest when polyps were exposed to combined stressors. Moderate $\mathrm{pH}$ also had minimal effect, highlighting the importance of testing the moderate climate scenarios, which are most likely to occur.

Although all polyps survived the experiment, reproductive rates (i.e. production of swimming polyps) were reduced under the lowest $\mathrm{pH}(7.7)$ and warm temperature $\left(28^{\circ} \mathrm{C}\right)$ treatment. Under $\mathrm{pH} 7.7$, the mobility of polyps was inhibited and respiration rates increased. These findings are consistent with observations of polyps of Alatina alata, the only other species of cubozoan for which the interactive effects of ocean acidification and warming have been studied (Klein et al., 2017).

Some marine fauna increase respiration rates to compensate for increased metabolic demands caused by exposure to elevated $p \mathrm{CO}_{2}$ and temperature (Wood et al., 2008). This ability may help organisms maintain fitness under stressed conditions. Consistent with our findings, respiration rates of the copepod Centropages tenuiremis increased to meet the demand of increased feeding rates at $\mathrm{pH} 7.83$ $\left(\sim 1000 \mu \mathrm{atm} p \mathrm{CO}_{2}\right.$; Li and $\left.\mathrm{Gao}, 2012\right)$. However, the respiration of polyps decreased near the end of the experiment, which may suggest that the most extreme treatment exerted deleterious effects on physiological mechanisms that maintain fitness of polyps. This also perhaps reduced the production of polyps in the extreme $\mathrm{pH}$ treatment as reproduction requires normal physiology and metabolism.

Reduced mobility of polyps exposed to the most extreme $\mathrm{pH}$ appeared to be caused by the polyps' tentacles being less active, indicating that polyps exposed to extreme ocean acidification may be less
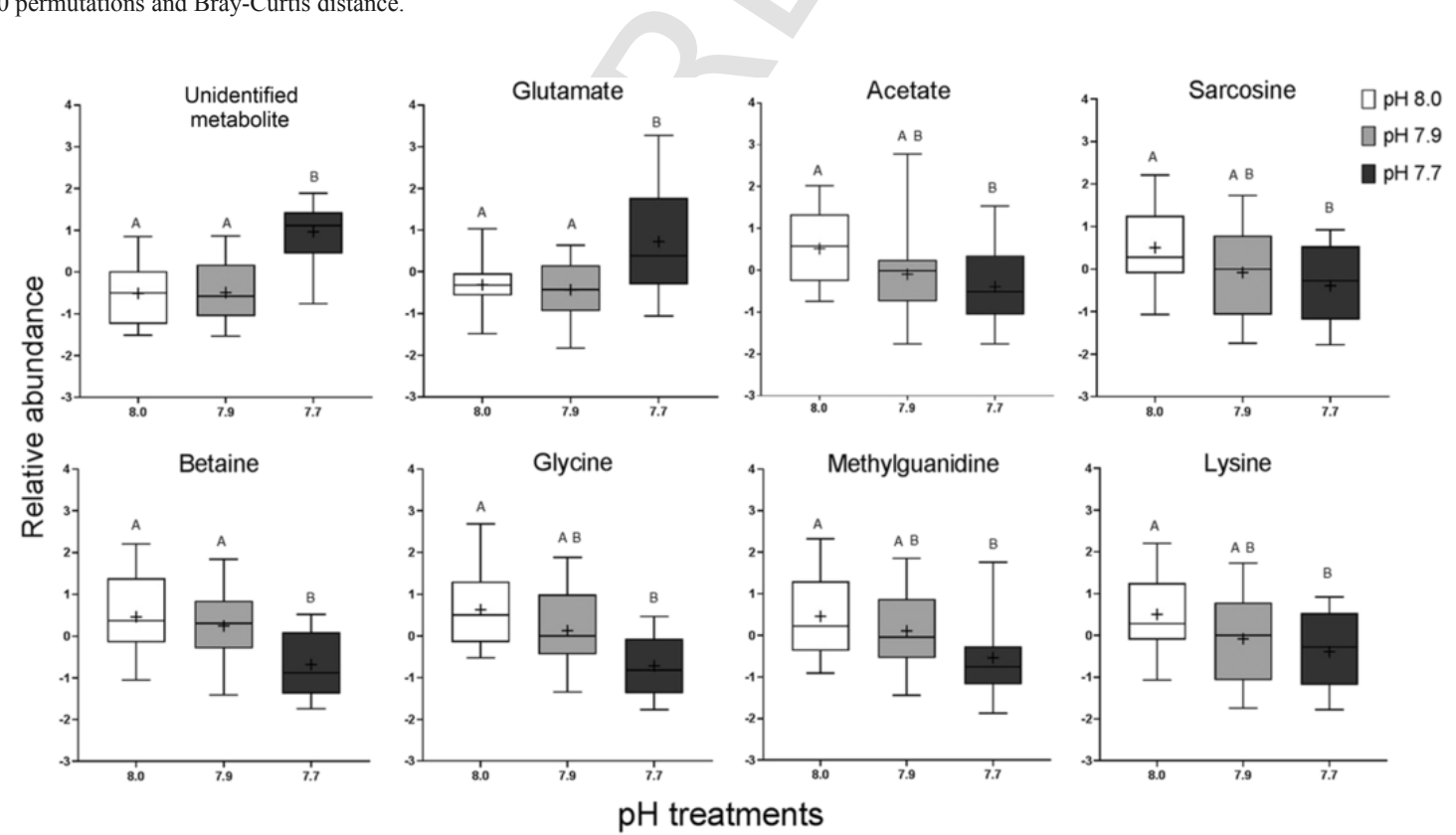

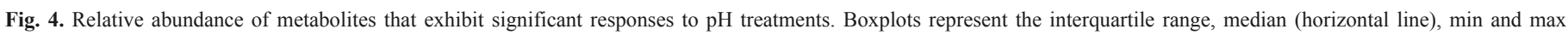
(whiskers), and average (+). Letters above whiskers indicate similarities (e.g. AA) and differences (e.g. AB) among the treatments based on Tukey's HSD test. 

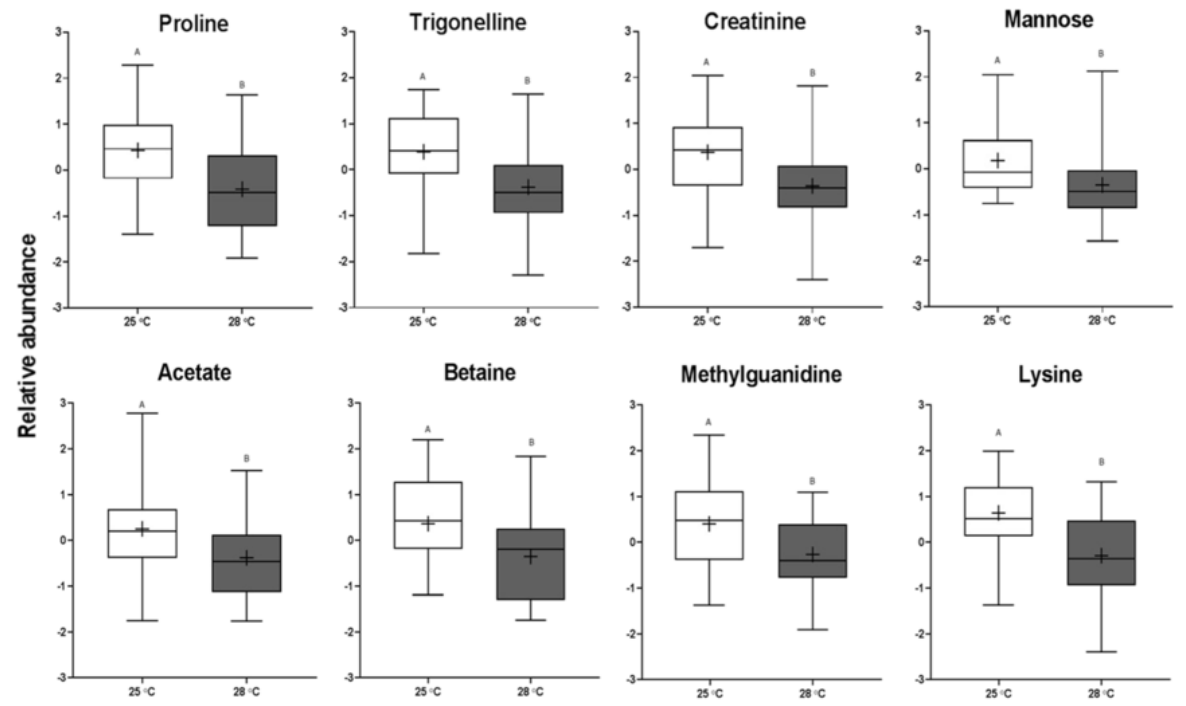

$\square 25^{\circ} \mathrm{C}$

$28^{\circ} \mathrm{C}$
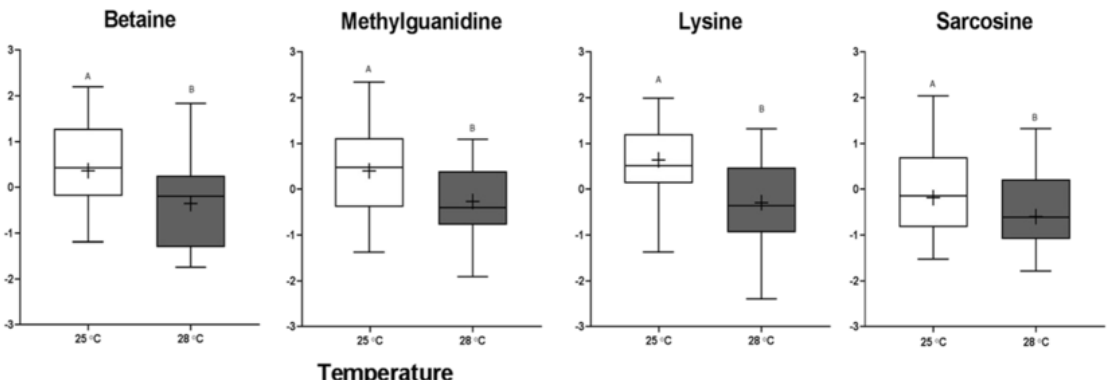

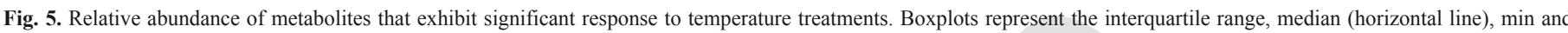

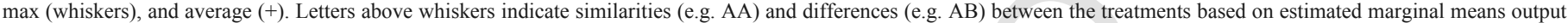
of two-factor ANOVA.

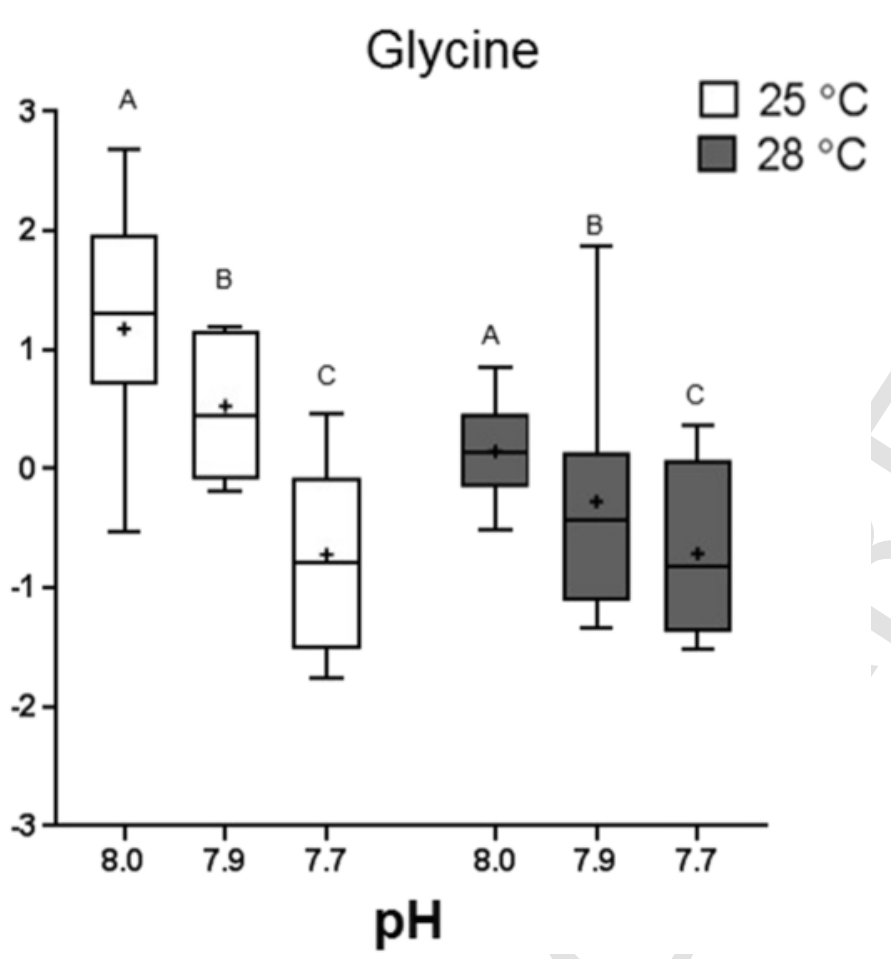

Fig. 6. Relative abundance of glycine that exhibit significant response to interaction of $\mathrm{pH}$ and temperature treatments. Boxplots represent the interquartile range, median (horizontal line), min and max (whiskers), and average $(+)$. Letters above whiskers indicate similarities (e.g. AA) and differences (e.g. AB) between the treatments based on estimated marginal means output of two-factor ANOVA.

capable of capturing prey. Reduced feeding activity under extreme $\mathrm{pH}$ (7.7-7.75) has been observed in the scleractinian corals Stylophora pistillata (Houlbrèque et al., 2015) and Galaxea fascicularis (Smith et al., 2016), which was potentially caused by elevated $p \mathrm{CO}_{2}$ hindering neurotransmitter function and, thereby, movements of the corals. Elevated $\mathrm{pCO}_{2}$ can impair neurosensory functions in fish and marine invertebrates (Nagelkerken and Munday, 2016). Here, we pre- sent evidence that it may impair neuromuscular functions as well, although the exact mechanism still needs to be determined.

\subsection{Effects on the metabolome of jellyfish polyps}

Metabolites are associated with many fundamental metabolic processes and, as such, the reduced abundance of some metabolites in polyps exposed to warmer temperature and elevated $p \mathrm{CO}_{2}$ may indicate impaired metabolic functioning in response to extreme climate conditions. Trigonelline, for example, regulates the production of polyps in hydrozoans (e.g. Hydractinia spp., Eirene spp. (Berking, 1991; Pfeifer and Berking, 2002) whereas betaine, which decreased in the extreme $\mathrm{pH}$ treatment, protects cells from osmotic and thermal stress (Burg and Ferraris, 2008). The reductions in these metabolites suggests that reproduction of $C$. barnesi jellyfish in the future may be impaired, which could ultimately reduce their populations.

The metabolites suppressed by exposure to low $\mathrm{pH}$ and elevated temperature were similar to many of the metabolites that decreased in the scleractinian corals Montipora capitata and Pocillopora damicornis exposed to low $\mathrm{pH}$ (7.6-7.35) conditions (Putnam et al., 2016). Our results are also consistent with those of many marine invertebrates such as bivalves and cephalopods that tend to suppress metabolism under low $\mathrm{pH}$ (Portner, 2008). In contrast, the metabolic suppression observed in our study is inconsistent with increased abundances of metabolites including glycine documented in the mussel Mytilus edulis exposed to low $\mathrm{pH}$ conditions (pH 7.8) (Ellis et al., 2014). The observed decrease in proline in the elevated temperature treatment of the current study also differs from increased proline identified in the soft coral Sarcophyton ehrenbergi and Sarcophyton glaucum (without endosymbionts) under low $\mathrm{pH}\left(\mathrm{CO}_{2}=1200 \mathrm{ppm}\right)$ and high temperature treatments $\left(32^{\circ} \mathrm{C}\right.$ to $\left.36^{\circ} \mathrm{C}\right)$ (Farag et al., 2016). In the present study, decreased proline may reflect that this metabolite was being used to produce glutamate (Brosnan and Brosnan, 2013), which increased in the extreme $\mathrm{pH}$ treatment.

The decrease of amino acids may indicate impaired protein synthesis, and indeed this helps to explain the reduction in protein content previously observed in Alatina alata polyps exposed to low $\mathrm{pH}$ condition (Klein et al., 2017). Moreover, this observation is consis- 
tent with the reduction in asexual reproduction, since this process requires normal protein synthesis (Langenbuch et al., 2006). The results here contrast with those of a study that found increased amino acids in mussels exposed to hypercapnia conditions (Ellis et al., 2014). That study suggested that the change of amino acid composition is part of a normal adaptation of the animal to fluctuating water conditions in estuarine habitats (Ellis et al., 2014). If the composition of amino acids indicates acclimation to highly variable conditions, Irukandji jellyfish polyps may have limited tolerance to varying conditions in warm estuaries where they are hypothesised to occur (Courtney et al., 2016a).

Glutamate appears sensitive to changes in extracellular $\mathrm{pH}$ in polyps, much as it is in mammalian tissues during extracellular acidosis (Kamm and Strope, 1972; Curthoys and Lowry, 1973: Brosnan, 2000). The increase in glutamate we observed is similar to that found in the mussel Mytilus edulis exposed to low pH (7.8) (Ellis et al., 2014). As indicated, increased glutamate is likely associated with the decrease in proline observed in this study. Taken together, this may suggest reduced glycolysis since cells can rely on glutaminolysis for energy production (Yang et al., 2017) and glutamate, produced through this process, compensates for cellular damage during stress like acidosis (Krebs and Bellamy, 1960; Melatunan et al., 2011; Brosnan and Brosnan, 2013). Other observed metabolite alterations are also consistent with broad effects on energy metabolism and cellular homeostasis. For example, several amino acids and the carbohydrate mannose decreased. Such effects are not uncommon in metabolomics studies due to the role common metabolites play in energetics and other cellular processes, but they highlight the energetic costs required for maintaining fitness under stress (Farag et al., 2016). Indeed, such maintenance often occurs through compensatory mechanisms associated with individual metabolic suppression (Portner, 2008). This compensation may have ultimately manifested at the organism level as reduced rates of asexual production of polyps in the lowest $\mathrm{pH}$ and elevated temperature treatments. Indeed, similar processes were identified in sipunculid worms, which reduced protein synthesis and metabolic rate to compensate for the effects of extracellular acidosis (Langenbuch et al., 2006).

Our findings support other studies that have concluded that moderate climate scenarios have minimal effects on marine biota (Hamilton et al., 2017; Lopes et al., 2018). For example, the juvenile rockfish $\mathrm{Se}$ bastes caurinus exposed to moderate $\mathrm{pCO}_{2}(\sim 750 \mathrm{ppm})$ exhibited no changes in behavioral lateralization (left vs. right turning decision), swimming speed or expression of regulatory genes (Hamilton et al., 2017), although the $p \mathrm{CO}_{2}$ used was somewhat higher than the most optimistic scenario (IPCC, 2014; Hughes et al., 2017). Moderate climate scenarios, therefore, may have minimal effects on animal physiology and behavior. Indeed, the effects of $p \mathrm{CO}_{2}$ and warming on marine invertebrates have thresholds (Wood et al., 2008; Thomsen and Melzner, 2010) and examining a range of scenarios, from moderate to extreme, may help pinpoint thresholds above which fauna will respond to climate change. Our findings show that the moderate scenario did not reach the sublethal thresholds that manifested in the extreme treatment perhaps due to adaptations to fluctuating $\mathrm{pH}$ conditions that reach moderate levels of $p \mathrm{CO}_{2}$. Coastal or shallow waters have large $p \mathrm{CO}_{2}$ fluctuations due to photosynthesis and tidal water oscillations which can influence adaptation to slightly elevated $p \mathrm{CO}_{2}$ (Portner, 2008; Jarrold et al., 2017).

\section{Conclusions}

Our work used environmentally relevant simulations, sublethal responses and NMR spectroscopy in studying responses of Irukandji jellyfish to predicted climate change conditions. Our results suggest that Irukandji polyps will survive in moderate and extreme climate conditions projected to occur by the year 2100 , but that their rates of asexual reproduction will be slower if temperatures warm by $2{ }^{\circ} \mathrm{C}$ and/or $\mathrm{pH}$ declines to $\sim 7.7$. If the moderate $p \mathrm{CO}_{2}$ scenario occurs in the future, however, $C$. barnesi populations will likely persist and continue to require management in northern Australia, particularly in Queensland where most cases of Irukandji syndrome are attributed to C. barnesi (Sando et al., 2010; Gershwin et al., 2013). The acclimation of other cnidarian species such as corals (Torda et al., 2017) also strengthens the assumption that $C$. barnesi populations will persist even in extreme conditions in the future. Although acclimation and adaptation have not been tested here, it is possible that Irukandji populations would be conditioned through phenotypic plasticity and/or transgenerational acclimation (Torda et al., 2017). We emphasize the need to test the responses of other Irukandji species to climate change stressors using sublethal endpoints to determine their responses as a taxon with similar ecological functions.

\section{CRediT authorship contribution statement}

Sheldon Rey Boco: Conceptualization, Methodology, Data curation. Kylie A. Pitt: Supervision, Conceptualization, Methodology, Data curation. Steven D. Melvin: Supervision, Methodology, Data curation.

\section{Declaration of Competing Interest \\ None. \\ Acknowledgments}

Funding for this study was provided by Griffith University, National Environmental Science Programme Tropical Water Quality Hub to K. A. P. and International Postgraduate Scholarship Award to S. R. B. We thank S. G. Klein, W. Bennett, F. Leusch, R. Stewart, A. Boyle, M. Reay, D. Angulo and C. Jacobson for technical assistance and J. McBroom and J. Hay for statistical advice.

\section{Appendix A. Supplementary data}

Supplementary data to this article can be found online at https:// doi.org/10.1016/j.scitotenv.2019.05.451.

\section{References}

Algueró-Muñiz, M., Meunier, C.L., Holst, S., Alvarez-Fernandez, S., Boersma, M., 2016. Withstanding multiple stressors: ephyrae of the moon jellyfish (Aurelia aurita, Scyphozoa) in a high-temperature, high- $\mathrm{CO}_{2}$ and low-oxygen environment. Mar. Biol. 163 (9), 185.

Anlauf, H., D'Croz, L., O'Dea, A., 2011. A corrosive concoction: the combined effects of ocean warming and acidification on the early growth of a stony coral are multiplicative. J. Exp. Mar. Biol. Ecol. 397, 13-20.

Berking, S., 1991. Control of metamorphosis and pattern formation in Hydractinia (Hydrozoa, Cnidaria). BioEssays 13 (7), 323-329.

Bockmon, E., Frieder, C., Navarro, M., White-Kershek, L., Dickson, A., 2013. Controlled experimental aquarium system for multistressor investigation of carbonate chemistry, oxygen saturation, and temperature. Biogeosciences 10, 5967-5975.

Brosnan, J.T., 2000. Glutamate, at the interface between amino acid and carbohydrate metabolism. J. Nutr. 130 (4), 988S-990S.

Brosnan, J.T., Brosnan, M.E., 2013. Glutamate: a truly functional amino acid. Amino Acids 45 (3), 413-418

Bundy, J.G., Davey, M.P., Viant, M.R., 2009. Environmental metabolomics: a critical review and future perspectives. Metabolomics 5, 3-21.

Burg, M.B., Ferraris, J.D., 2008. Intracellular organic osmolytes: function and regulation. J. Biol. Chem. 283, 7309-7313.

Byrne, M., Ross, P.M., Dworjanyn, S.A., Parker, L., 2017. Larval Ecology in the Face of Changing Climate-Impacts of Ocean Warming and Ocean Acidification. Evo- 
lutionary Ecology of Marine Invertebrate Larvae. Oxford University Press, New York, NY, 251-272.

Camp, E.F., Schoepf, V., Mumby, P.J., Hardtke, L.A., Rodolfo-Metalpa, R., Smith, D.J., Suggett, D.J., 2018. The future of coral reefs subject to rapid climate change: lessons from natural extreme environments. Front. Mar. Sci. 5, 4.

Carrette, T.J., Underwood, A.H., Seymour, J.E., 2012. Irukandji syndrome: a widely misunderstood and poorly researched tropical marine envenoming. Diving Hyperb. Med. 42 (4), 214-223.

Courtney, R., Browning, S., Seymour, J., 2016. Early life history of the 'Irukandji' jellyfish Carukia barnesi. PLoS One 11 (3), e0151197.

Courtney, R., Browning, S., Northfield, T., Seymour, J., 2016. Thermal and osmotic tolerance of 'Irukandji' Polyps: Cubozoa; Carukia barnesi. PLoS One 11 (7), e0159380.

Curthoys, N.P., Lowry, O.H., 1973. Glutamate and glutamine distribution in the rat nephron in acidosis and alkalosis. Am. J. Phys. 224 (4), 884-889.

Dickson, A.G., Sabine, C.L., Christian, J.R., 2007. Guide to Best Practices for Ocean $\mathrm{CO}_{2}$ Measurements. PICES Special Publication 3 North Pacific Marine Science Organization, Sidney, BC, Canada, (191 pp).

Doney, S.C., 2010. The growing human footprint on coastal and open ocean biogeochemistry. Science 328, 1512-1516.

Doney, S.C., Ruckelshaus, M., Duffy, J.E., Barry, J.P., Chan, F., English, C.A., ... Polovina, J., 2012. Climate change impacts on marine ecosystems. Annu. Rev. Mar. Sci. 4, 11-37.

Duarte, C.M., Hendriks, I.E., Moore, T.S., Olsen, Y.S., Steckbauer, A., Ramajo, L., Carstensen, J., Trotter, J.A., McCulloch, M., 2013. Is ocean acidification an open-ocean syndrome? Understanding anthropogenic impacts on seawater $\mathrm{pH}$. Estuar. Coasts $36(2), 221-236$

Ellis, R.P., Spicer, J.I., Byrne, J.J., Sommer, U., Viant, M.R., White, D.A., Widdicombe, S., 2014. 1H NMR metabolomics reveals contrasting response by male and female mussels exposed to reduced seawater $\mathrm{pH}$, increased temperature, and a pathogen. Environ. Sci. Technol. 48 (12), 7044-7052.

Farag, M.A., Porzel, A., Al-Hammady, M.A., Hegazy, M.E.F., Meyer, A., Mohamed, T.A., ... Wessjohann, L.A., 2016. Soft corals biodiversity in the Egyptian Red Sea: a comparative MS and NMR metabolomics approach of wild and aquarium grown species. J. Proteome Res. 15 (4), 1274-1287.

Fenner, P.J., 1999. Irukandji envenomation in far north Queensland. Med. J. Aust. 170, 512.

Georgiou, L., Falter, J., Trotter, J., Kline, D.I., Holcomb, M., Dove, S.G., ... McCulloch, M., 2015. pH homeostasis during coral calcification in a free ocean $\mathrm{CO}_{2}$ enrichment (FOCE) experiment, Heron Island reef flat, Great Barrier Reef. Proc. Natl. Acad. Sci. 112 (43), 13219-13224.

Gershwin, L.A., Richardson, A.J., Winkel, K.D., Fenner, P.J., Lippmann, J., Hore, R. ... Condie, S., 2013. Biology and ecology of Irukandji jellyfish (Cnidaria: Cubozoa). In: Advances in Marine Biology. vol. 66, Academic Press, pp. 1-85.

Hamilton, S.L., Logan, C.A., Fennie, H.W., Sogard, S.M., Barry, J.P., Makukhov, A.D., ... Bernardi, G., 2017. Species-specific responses of juvenile rockfish to elevated pCO2: from behavior to genomics. PLoS One 12 (1), e0169670.

Hartmann, D.L., Klein Tank, A.M.G., Rusticucci, M., Alexander, L.V., Brönnimann, S., Charabi, Y., Dentener, F.J., Dlugokencky, E.J., Easterling, D.R., Kaplan, A., Soden, B.J., Thorne, P.W., Wild, M., Zhai, P.M., 2013. Observations: atmosphere and surface. In: Stocker, T.F., Qin, D., Plattner, G.-K., Tignor, M., Allen, S.K., Boschung, J., Nauels, A., Xia, Y., Bex, V., Midgley, P.M. (Eds.), Climate Change 2013: The Physical Science Basis. Contribution of Working Group I to the Fifth Assessment Report of the Intergovernmental Panel on Climate Change. Cambridge University Press, Cambridge, United Kingdom and New York, NY, USA.

Houlbrèque, F., Reynaud, S., Godinot, C., Oberhänsli, F., Rodolfo-Metalpa, R., Ferrier-Pagès, C., 2015. Ocean acidification reduces feeding rates in the scleractinian coral Stylophora pistillata. Limnol. Oceanogr. 60 (1), 89-99.

Hughes, T.P., Barnes, M.L., Bellwood, D.R., Cinner, J.E., Cumming, G.S., Jackson, J.B., .. Palumbi, S.R., 2017. Coral reefs in the Anthropocene. Nature 546 (7656), 82.

IPCC, 2014. Climate change 2014: synthesis report. In: Contribution of Working Groups I, II and III to the Fifth Assessment Report of the Intergovernmental Panel on Climate Change. IPCC, Geneva, Switzerland.

Jarrold, M.D., Humphrey, C., McCormick, M.I., Munday, P.L., 2017. Diel $\mathrm{CO}_{2}$ cycles reduce severity of behavioural abnormalities in coral reef fish under ocean acidification. Sci. Rep. 7 (1), 10153.

Kamm, D.E., Strope, G.L., 1972. The effects of acidosis and alkalosis on the metabolism of glutamine and glutamate in renal cortex slices. J. Clin. Invest. 51 (5), $1251-1263$.

Kikkawa, T., Minowa, Y., Nakamura, Y., Kita, J., Ishimatsu, A., 2010. Swimming inhibition by elevated $\mathrm{pCO}_{2}$ in ephyrae of the scyphozoan jellyfish, Aurelia. Plankon Benthos Res. 5 (3), 119-122.

Klein, S.G., Pitt, K.A., Rathjen, K.A., Seymour, J.E., 2014. Irukandji jellyfish polyps exhibit tolerance to interacting climate change stressors. Glob. Chang. Biol. 20 (1) $28-37$.

Klein, S.G., Pitt, K.A., Carroll, A.R., 2017. Pre-exposure to simultaneous, but not individual, climate change stressors limits acclimation capacity of Irukandji jellyfish polyps to predicted climate scenarios. Coral Reefs 36 (3), 987-1000.
Kroeker, K.J., Kordas, R.L., Crim, R., Hendriks, I.E., Ramajo, L., Singh, G.S., ... Gattuso, J.P., 2013. Impacts of ocean acidification on marine organisms: quantifying sensitivities and interaction with warming. Glob. Chang. Biol. 19 (6), 1884-1896.

Kültz, D., 2005. Molecular and evolutionary basis of the cellular stress response. Annu. Rev. Physiol. 67, 225-257.

Langenbuch, M., Bock, C., Leibfritz, D., Pörtner, H.O., 2006. Effects of environmental hypercapnia on animal physiology: a 13C-NMR study of protein synthesis rates in the marine invertebrate Sipunculus nudus. Comp. Biochem. Physiol. A 144, 479-484.

Li, W., Gao, K., 2012. A marine secondary producer respires and feeds more in a high $\mathrm{CO}_{2}$ ocean. Mar. Pollut. Bull. 64 (4), 699-703.

Lopes, I.G., Araújo-Dairiki, T.B., Kojima, J.T., Val, A.L., Portella, M.C., 2018. Predicted 2100 climate scenarios affects growth and skeletal development of tambaqui (Colossoma macropomum) larvae. Ecol. Evol. 8 (20), 10039-10048.

Melatunan, S., Calosi, P., Rundle, S.D., Moody, A.J., Widdicombe, S., 2011. Exposure to elevated temperature and $\mathrm{pCO} 2$ reduces respiration rate and energy status in the periwinkle Littorina littorea. Physiol. Biochem. Zool. 84 (6), 583-594.

Melvin, S.D., Wilson, S.P., 2013. The utility of behavioral studies for aquatic toxicology testing: a meta-analysis. Chemosphere 93 (10), 2217-2223.

Nagelkerken, I., Munday, P.L., 2016. Animal behaviour shapes the ecological effects of ocean acidification and warming: moving from individual to community-level responses. Glob. Chang. Biol. 22, 974-989.

Pandolfi, J.M., Connolly, S.R., Marshall, D.J., Cohen, A.L., 2011. Projecting coral reef futures under global warming and ocean acidification. Science 333, 418-422.

Pereira, P., Barry, J., Corkeron, M., Keir, P., Little, M., Seymour, J.E., 2010. Intracerebral hemorrhage and death after envenoming by the jellyfish Carukia barnesi. Clin. Toxicol. 48 (4), 390-392.

Pfeifer, R., Berking, S., 2002. Control of formation of the two types of polyps in Thecocodium quadratum (Hydrozoa, Cnidaria). Int. J. Dev. Biol. 39 (2), 395-400.

Pierobon, P., Tino, A., Minei, R., Marino, G., 2004. Different roles of GABA and glycine in the modulation of chemosensory responses in Hydra vulgaris (Cnidaria, Hydrozoa). Hydrobiologia 530 (1-3), 59-66.

Pitt, K.A., Lucas, C.H., Condon, R.H., Duarte, C.M., Stewart-Koster, B., 2018. Claims that anthropogenic stressors facilitate jellyfish blooms have been amplified beyond the available evidence: a systematic review. Front. Mar. Sci. 5, 451.

Portner, H.O., 2008. Ecosystem effects of ocean acidification in times of ocean warming: a physiologist's view. Mar. Ecol. Prog. Ser. 373, 203-217.

Pörtner, H.O., Langenbuch, M., Michaelidis, B., 2005. Synergistic effects of temperature extremes, hypoxia, and increases in $\mathrm{CO}_{2}$ on marine animals: from earth history to global change. J. Geophys. Res. Oceans 110 (C9).

Przeslawski, R., Byrne, M., Mellin, C., 2015. A review and meta-analysis of the effects of multiple abiotic stressors on marine embryos and larvae. Glob. Chang. Biol. 21 (6), 2122-2140

Putnam, H.M., Davidson, J.M., Gates, R.D., 2016. Ocean acidification influences host DNA methylation and phenotypic plasticity in environmentally susceptible corals. Evol. Appl. 9 (9), 1165-1178.

Rand, G.M., 1995. Fundamentals of Aquatic Toxicology: Effects, Environmental Fate and Risk Assessment. CRC Press.

Reisinger, A., Kitching, R.L., Chiew, F., Hughes, L., Newton, P.C.D., Schuster, S.S., Tait, A., Whetton, P., 2014. Australasia. In climate change 2014: impacts, adaptation, and vulnerability. Part B: regional aspects. In: Barros, V.R., Field, C.B., Dokken, D.J., Mastrandrea, M.D., Mach, K.J., Bilir, T.E., Chatterjee, M., Ebi, K.L., Estrada, Y.O., Genova, R.C., Girma, B., Kissel, E.S., Levy, A.N., MacCracken, S., Mastrandrea, P.R., White, L.L. (Eds.), Contribution of Working Group II to the Fifth Assessment Report of the Intergovernmental Panel on Climate Change. Cambridge University Press, Cambridge, United Kingdom and New York, NY, USA, pp. 1371-1438.

Riebesell, U., Gattuso, J.P., 2015. Lessons learned from ocean acidification research. Nat. Clim. Chang. 5, 12-14.

Rossi, T., Nagelkerken, I., Simpson, S.D., Pistevos, J.C.A., Watson, S.-A., Merillet, L., Fraser, P., Munday, P.L., Connell, S.D., 2015. Ocean acidification boosts larval fish development but reduces the window of opportunity for successful settlement. Proc. R. Soc. B 282 (1821), 20151954.

Sando, J.J., Usher, K., Buettner, P., 2010. 'To swim or not to swim': the impact of jellyfish stings causing Irukandji syndrome in Tropical Queensland. J. Clin. Nurs. 19, $109-117$.

Smith, J.N., Strahl, J., Noonan, S.H., Schmidt, G.M., Richter, C., Fabricius, K.E., 2016. Reduced heterotrophy in the stony coral Galaxea fascicularis after life-long exposure to elevated carbon dioxide. Sci. Rep. 6, 27019.

Sogin, E.M., Putnam, H.M., Anderson, P.E., Gates, R.D., 2016. Metabolomic signatures of increases in temperature and ocean acidification from the reef-building coral, Pocillopora damicornis. Metabolomics 12 (4), 71

Southcott, R.V., 1967. Revision of some Carybdeidae (Scyphozoa: Cubomedusae) including a description of the jellyfish responsible for the 'Irukandji syndrome'. Aust J. Zool. 15 (3), 651-671.

Thomsen, J., Melzner, F., 2010. Moderate seawater acidification does not elicit long-term metabolic depression in the blue mussel Mytilus edulis. Mar. Biol. 157 (12), 2667-2676. 
Tills, O., Sun, X., Rundle, S.D., Heimbach, T., Gibson, T., Cartwright, A., ... Spicer, J.I., 2016. Reduced $\mathrm{pH}$ affects pulsing behaviour and body size in ephyrae of the moon jellyfish, Aurelia aurita. J. Exp. Mar. Biol. Ecol. 480, 54-61.

Torda, G., Donelson, J.M., Aranda, M., Barshis, D.J., Bay, 1., Berumen, M.L., David, G., Bourne, D.G., ... Munday, P.L., 2017. Rapid adaptive responses to climate change in corals. Nat. Clim. Chang. 7 (9), 627.

Towle, E.K., Enochs, I.C., Langdon, C., 10 (4). Threatened Caribbean coral is able to mitigate the adverse effects of ocean acidification on calcification by increasing feeding rate. PLoS One2015,e0123394,1-17.

Underwood, A.H., Seymour, J.E., 2007. Venom ontogeny, diet and morphology in Carukia barnesi, a species of Australian box jellyfish that causes Irukandji syndrome. Toxicon 49 (8), 1073-1082.

Viant, M.R., 2007. Metabolomics of aquatic organisms: the new 'omics' on the block. Mar. Ecol. Prog. Ser. 332, 301-306.
Wahl, M., Saderne, V., Sawall, Y., 2016. How good are we at assessing the impact of ocean acidifcation in coastal systems? Limitations, omissions and strengths of commonly used experimental approaches with special emphasis on the neglected role of fluctuations. Mar. Freshw. Res. 67, 25-36.

Waldbusser, G.G., Salisbury, J.E., 2014. Ocean acidification in the coastal zone from an organism's perspective: multiple system parameters, frequency domains, and habitats. Annu. Rev. Mar. Sci. 6, 221-247.

Walker, C.H., 2008. Organic Pollutants: An Ecotoxicological Perspective. CRC Press.

Wood, H.L., Spicer, J.I., Widdicombe, S., 2008. Ocean acidification may increase calcification rates, but at a cost. Proc. R. Soc. B 275, 1767-1773.

Xia, J., Wishart, D.S., 2016. Using MetaboAnalyst 3.0 for comprehensive metabolomics data analysis. Curr. Protoc. Bioinformatics 55 (1), 14-10.

Yang, L., Venneti, S., Nagrath, D., 2017. Glutaminolysis: a hallmark of cancer metabolism. Annu. Rev. Biomed. Eng. 19, 163-194. 